PLURAL, Revista do Programa de Pós-Graduação em Sociologia da USP, São Paulo, v. 16, n. 1, pp. 39-52, 2009

\title{
Um Espectro Ronda a Teoria Social Contemporânea: Tocqueville, Rosanvallon e a Modernidade
}

\section{Helga Gahyva*}

Resumo: O artigo procura revelar as afinidades entre as ideias de Pierre Rosanvallon, tal como expressas em $A$ Crise do Estado-Providência, e o diagnóstico tocquevilliano acerca da experiência moderna, elaborado ainda na primeira metade do século XIX. O objetivo consiste em mostrar, por meio de um autor contemporâneo, como a discussão atual sobre as relaçóes entre Estado e sociedade civil reatualizam os temas da descentralização e do pluralismo societário presentes em A Democracia na América.

Palavras-chave: Pierre Rosanvallon; Alexis de Tocqueville; modernidade; Estado; sociedade civil.

\section{A Spectre is Haunting the Contemporary Social Theory: Tocqueville, Rosanvallon and Modernity}

Abstract: The article aim to reveal the affinities between the ideas of Pierre Rosanvallon, as expressed in The Crisis of the Welfare State, and the tocquevillian diagnosis of de modern experience, elaborated in the first half of the nineteen century. The objective is to show, through a contemporary author, how the current discussion about the relations between State and civil society bring revitalize the themes of decentralization and social pluralism present in Democracy in America.

Keywords: Pierre Rosanvallon; Alexis de Tocqueville; modernity; State; civil society.

Desde meados dos anos 1950 do século XX, aproximadamente, identifica-se crescente reinteresse pela obra do político e escritor francês Alexis de Tocqueville (I805-1859). Desde então,

\footnotetext{
* Doutora em Sociologia pelo Iuperj. Professora do Departamento de Sociologia e Política da PUC-Rio.
} 
configurou-se certa "expansão do domínio tocquevilliano": se antes praticamente restrito aos cursos de História, hoje, ele assumiu um papel teórico importante também no campo da disciplina sociológica (FUrET, I99I, p. I38).

O objetivo deste trabalho consiste em identificar certas razóes subjacentes ao ressurgimento de Tocqueville no cenário intelectual, na qualidade de pensador-chave para a compreensão dos desafios característicos da atualidade. Como pano de fundo histórico, utilizo-me da periodização quanto às fases do capitalismo proposta por Boaventura de Souza Santos, em seu esforço de perceber as relaçóes entre a sociedade contemporânea e o projeto moderno - por meio dela, pretendo evidenciar as correlaçóes entre as reflexôes do autor de A Democracia na América e o capitalismo desorganizado (SANTOS, I997, pp. 69-IOI).

O resgate das inquietaçóes tocquevillianas na Sociologia contemporânea será aqui analisado em diálogo com o pensamento de Pierre Rosanvallon, tal como exposto, fundamentalmente, em A Crise do Estado-Providência (Rosanvallon, 1997)․ Como hipótese central, sugiro que os objetivos dessa obra podem ser compreendidos como tentativas de resposta aos dois principais temores tocquevillianos: o despotismo democrático e a tirania da maioria.

Para ilustrar a parca atenção dedicada ao autor de O Antigo Regime e a Revolução durante a primeira metade do século passado, tome-se como exemplo um volume de La Nouvelle Revue Française, publicado em 1934, no qual consta um artigo do crítico literário Albert Thibaudet, dedicado às relaçóes próximas entre Tocqueville e um autor hoje relegado ao ostracismo, Arthur de Gobineau².

Segundo Thibaudet: "lemos, reeditamos, discutimos Gobineau! Tocqueville está recoberto pelo esquecimento". Essa observação tinha como pano de fundo a convicção quanto ao inexorável fracasso do liberalismo, pois, "por toda Europa, o rótulo liberal praticamente desapareceu do mundo parlamentar. O termo liberalismo pertence ao passado" (ThibaudeT, I934, p. 58).

Historicamente, a reflexão de Thibaudet é contemporânea à era fascista (HoBSBAwn, 2000; MAZOWER, 200I), momento no qual forças conservadoras assumem protagonismo na arena pública, sustentadas pela expectativa quanto ao colapso dos valores e das instituiçóes caros à agenda liberal ${ }^{3}$. Para os fins aqui propostos, importa destacar que a ideologia fascista pretende configurar-se como movimento supostamente capaz de incorporar as demandas populares dos países nos quais ela fora adotada. Ora, essa ambiçáo pressupóe a crença na possibilidade de unificação dessas demandas, ou, melhor dizendo, ela se coaduna com uma perspectiva na qual a sociedade civil é vista como composta de interesses homogêneos - ou, pelo menos, passíveis de harmonização.

\footnotetext{
I A primeira ediçẫo do livro data de I98I.

2 Tocqueville e Gobineau foram bastante próximos. Nos anos I840, o jovem Gobineau trabalhou como assistente de pesquisa do já célebre autor de A Democracia na América. Eles trocaram correspondências até a morte de Tocqueville, em I859. Conforme Tocqueville (1959).

3 Para enfatizar o recuo do liberalismo no período, Hobsbawn lembra-nos que: "Tomando-se o mundo como um todo, havia talvez 35 ou mais governos constitucionais e eleitos em I920 (...). Até 1938, havia talvez I7 desses Estados, em 1944, talvez I2, de um total global de 65. A tendência mundial parecia clara” (HobsBaWN, 2000, p. II5).
} 
Por outro lado, a conjuntura na qual se inscreve a reflexão de Thibaudet pertence à época do capitalismo organizado, compreendida entre as décadas finais do século XIX e as primeiras décadas após a Segunda Guerra Mundial. Segundo Santos, nessa etapa, a percepção da fragilidade do mercado como um "harmonizador espontâneo" das relaçôes sociais - característico da fase do capitalismo liberal, própria ao século XIX - teria levado o Estado a assumir o papel de organizador da contingência.

A tônica da fase do capitalismo organizado reside na constataçấo de que nem todas as promessas contidas no projeto moderno eram compatíveis com a expansão do capitalismo. Fez-se necessária, portanto, uma clara demarcaçáo daquilo que seria realizável em tal ordem econômica - e, consequentemente, quais propostas seriam definitivamente postas de lado. A compensaçáo oferecida pelo abandono dessas propostas teria sido realizada por meio de uma ampliaçáo daquelas medidas encaradas como viáveis, radicalizando o terreno do possível com vistas a abrandar os irreparáveis déficits (SANTOS, op. cit., pp. 6-79).

Nesse contexto, o Estado assumiu novas feiçóes: esse é o momento do surgimento do Estado-Providência. Apesar de cada vez mais articulado com o mercado (SANTOs, op. cit., p. 76), o Welfare State constituiu-se como um agente capaz de oferecer aos indivíduos soluçóes paliativas para que melhor convivessem com a impossibilidade de realizar as promessas modernas definitivamente abandonadas. Porém, ao mesmo tempo em que o Estado tornou-se cada vez mais presente, intervindo diretamente na sociedade, ele o fez por meio do fortalecimento de um aparato burocrático que o colocou ainda mais distante dos atores sociais.

No capitalismo organizado, portanto, "o projeto da modernidade cumpre-se assim em excesso porque em tudo o que cumpre excede todas as expectativas (basta ver o fulgurante avanço do conhecimento científico) e em tudo o que não cumpre é suficientemente convincente para negar que haja algo ainda a cumprir" (SANTOS, op. cit., p. 78).

II

Pode-se sugerir que o mundo do capitalismo organizado podia comportar um pensamento como o de Gobineau. A despeito de seu contundente pessimismo (GAHYVA, 2006, pp. 555-558), ele preocupava-se em desvendar, por meio de procedimentos que julgava os mais científicos, leis gerais que explicassem o desenvolvimento - ou, em seu caso, a degenerescência - das sociedades humanas (GobINEAU, I983). Em sua perspectiva, um Estado centralizador e autoritário coadunava-se com um mundo democrático ${ }^{4}$, caracterizado por uma massa de homens iguais.

Em contraste, a crise da segunda fase do capitalismo e, em seguida, sua passagem a uma terceira fase - aquela na qual ainda vivemos -, legou à obsolescência as teorias sociológicas que, como a de Gobineau, pretendiam-se universais espacialmente e temporalmente.

4 Democrático no sentido tocquevilliano do termo, ou seja, sem barreiras estamentais entre os indivíduos, afinal, no mudo moderno: "a igualdade (...) não significa que as fortunas são iguais (...) mas simplesmente que não estão enraizadas na transmissão familiar, e que o dinheiro circula rapidamente" (FuRET, 1982, p. 23I). 
Lyotard chamou esse fenômeno de crise das metanarrativas, diagnosticando a esterilidade em tentar analisar as transformaçóes contemporâneas segundo um viés universalista e abstrato (LYOTARD, 1986, pp. 35-42).

De acordo com o diagnóstico de Santos, desde os anos 1960 vivemos na época do capitalismo desorganizado, período caracterizado pela constataçáo de que os déficits do projeto da modernidade sáo muito mais extensos do que se julgava na etapa anterior. E, dado que as soluçôes encontradas para amenizá-los não foram satisfatórias, seria uma incoerência continuarmos a persegui-los. É preciso que aceitemos o esgotamento da modernidade e busquemos um novo paradigma para substituí-la (SANTOS, op. cit., pp. 79-84).

Nesse esforço de compreensão dos novos desafios impostos pela contemporaneidade - que não é, evidentemente, preocupaçáo exclusiva de Santos -, ronda o espectro de Tocqueville. Ao contrário daquela previsão de Thibaudet, a expansão da ideologia liberal parece reeditar cada dia com mais força a incorporação da crítica tocquevilliana ao mundo democrático.

\section{III}

Para Tocqueville, a característica intrínseca da experiência moderna reside na expansão do estado social democrático, isto é, na introduçáo da igualdade como valor definidor da modernidade. A igualdade não pode ser ameaçada - ela é parte constitutiva desse mundo. A liberdade, por sua vez, apresenta-se como um valor fugaz, e será sua perda ou sua conquista que ditará o futuro da civilização.

$\mathrm{O}$ autor opera uma distinçáo entre aristocracia e liberdade, por um lado, e democracia e igualdade, por outro'. No mundo aristocrático, os corpos intermediários preservariam a liberdade, funcionando como filtros entre os súditos e o soberano, de modo a promover o pluralismo. A estabilidade dessa sociedade era garantida pelo forte sentimento de hierarquia. Com o advento da democracia, a noção de que cada um ocupa um lugar fixo na estrutura social foi substituída pela igualdade de condiçóes, formando uma cadeia relativamente comum de valores - ou, em outras palavras, homogeneidade entre meios e fins. Assim, de acordo com Tocqueville, os homens modernos aproximar-se-iam no exercício compartilhado da mobilidade social. É do espanto diante dessa massa de homens iguais que nasce a Sociologia tocquevilliana.

A emergência de uma nova configuração histórica conduz à reformulaçấo dos tradicionais instrumentos cognitivos. Como ele próprio acentua, é necessário fundar uma nova ciência para um mundo inteiramente novo (TocQueville, 1998, p. I2). E a tarefa implica um duplo desafio, que compreende tanto a dimensão do diagnóstico como a da aposta: é fundamental conhecer não só as particularidades dessa nova configuração social, mas, também, os riscos que ela comporta.

\footnotetext{
5 "A tensão entre os planos da liberdade e da igualdade é permanente, nunca podendo ser inteiramente cancelada, pois os princípios organizadores deles procedem de tipos de sociedade radicalmente diferentes: a aristocrática e a democrática” (Werneck Vianna, [2004], p. I03).
} 
Tocqueville percebe uma tendência ao decréscimo na força dos valores da liberdade diante da crescente mercantilizaçáo das relaçôes sociais. Ele receia que a busca incessante dos interesses privados, característica da moderna ética do trabalho, imponha-se sobre a vocação cívica dos indivíduos - em especial, os americanos -, afastando-os das questóes de natureza pública ${ }^{6}$, tal como se observa na citação a seguir:

Quando o gosto pelas fruiçôes materiais se desenvolve num desses povos [democráti$\cos$ m mais rapidamente do que as luzes e os hábitos da liberdade, chega um momento em que os homens ficam arrebatados e como que fora de si, ao verem esses novos bens de que estão prestes a se apoderar. Preocupados unicamente com fazer fortuna, não percebem mais o vínculo estreito que une a fortuna particular de cada um deles à prosperidade de todos. O exercício de seus deveres políticos lhes parece um contratempo incômodo que os distrai de sua indústria. (...) Essa gente crê seguir a doutrina do interesse, mas só tem dela uma ideia grosseira e, para zelar melhor pelo que chamam seus negócios, negligenciam o principal, que é permanecer donos de si mesmos (TocQueville, 2000, p. 172).

O paulatino crescimento da centralizaçáo administrativa seria a consequência inevitável do fato de os homens democráticos abdicarem de seu papel nos negócios públicos, originando o fenômeno que ele denominou despotismo democrático. Ao contrário das configuraçôes despóticas "tradicionais" (BobBio et al., I99I, p. 340; Vollrath, I986, p. I32), o novo despotismo náo se fundaria no medo, mas no consentimento dos cidadãos: os indivíduos abririam mão espontaneamente de sua função decisória nas arengas públicas, desde que ao abrigo de um Estado provedor da tranquilidade social. Tratar-se-ia do triunfo do individualismo egoísta (MerQuior, I99I, p. 89), dado que os interesses dos indivíduos democráticos estariam exclusivamente voltados para a realizaçáo de seus negócios privados.

A demanda por uma nova ciência refere-se à necessidade de perceber quais mecanismos poderiam inibir esse comportamento marcadamente individualista. Em sua viagem à América, Tocqueville imagina tê-los encontrado no associativismo, locus privilegiado para o exercício da participação na vida pública. Conforme afirma Besnier (1990, p. 76):

Verdadeiros "poderes intermediários" (...), as associaçóes resumem o combate que Tocqueville trava pela liberdade política: elas constituem verdadeiramente o antídoto ao individualismo a corrigir a fraqueza e a sacudir a apatia do cidadáo atomizado; elas educam para a via pública, oferecendo oportunidade de articular o interesse privado com o "interesse público".

6 Sintomaticamente, Tocqueville é o autor da epígrafe do livro de Sennett O Declinio do Homem Público. Conforme Sennett (1999). 
Destaca-se, na reflexão tocquevilliana sobre o associativismo, o conceito de interesse bem compreendido: atrelado à descentralização administrativa, designa um sentimento comum, segundo o qual a promoção do bem-estar coletivo refletirá na promoçấo do bem-estar individual. Atribuir aos cidadáos a responsabilidade pela administração das demandas locais estimularia a prática associativa e, por conseguinte, incrementaria a interdependência individual. Assim, seria por meio da harmonia do conjunto da sociedade que cada cidadáo obteria segurança na realização de seus objetivos.

Em tempos democráticos, os poderes intermediários seriam, também, potenciais neutralizadores da tirania da maioria. Como Tocqueville notou em sua estadia americana, a total liberdade de associaçáo na regiáo impedia a formaçáo de amplos consensos majoritários em torno de interesses comuns. Seguindo os passos de Madison, ele igualmente acreditava que o facciosismo garantia a liberdade (MADISON, HAMILTON \& JAY, 1993, pp. I69-I92), pois a existência de múltiplas associaçôes de interesses permitia que as minorias se opusessem a uma provável maioria opressiva ${ }^{7}$.

Se para Tocqueville, portanto, a tensão entre aristocracia e democracia foi solucionada com a imposiçáo desta última, a tensáo entre liberdade e servidáo ditará o destino das sociedades igualitárias.

IV

Pierre Rosanvallon levanta uma série de questóes compartilhadas com vários de seus contemporâneos. Desejo com isso afirmar que há, hoje, nas Ciências Sociais, certo consenso a respeito de algumas transformaçóes pelas quais vem passando o mundo atual, expresso, sobretudo, por meio do binômio pluralização/fragmentação.

Uma discussão central versa sobre a impossibilidade de pensarmos as transformaçôes sociais segundo perspectivas universalistas e abstratas. Para além dos relativismos grosseiros, parece cada vez mais difícil elaborar projetos de futuro que unifiquem os objetivos dos diferentes membros de uma dada sociedade. Ora, sabemos que a Sociologia tomou como tarefa, em seus primórdios, o desejo de fornecer unidade a um mundo tornado instável - ou, para usar a terminologia durkheimiana, a necessidade de estabelecer sob quais formas seria possível produzir solidariedade moral entre pessoas tornadas indivíduos diferentes.

O sujeito do marxismo reencaixa-se identitariamente por meio da classe social - classes produzem identidades de classe. Durkheim definia o homem moderno a partir de sua formaçấo profissional. Para ele, os grupamentos profissionais - as corporaçóes - seriam os instrumentos capazes de corrigir a anomia no mundo moderno. Weber, precursoramente, renuncia à unidade, porém vê em seu lugar não pluralismo, mas fragmentaçáo e a encara em uma ótica pessimista: se

7 A principal preocupação de Tocqueville nesse ponto refere-se à possibilidade de aplicação da igualdade às inteligências. Conforme Jasmin (1997, p. 65). 
algum antídoto pode lhe ser oferecido, ele passa pela ação dos líderes carismáticos modernos - os demagogos -, no âmbito da democracia plebiscitária.

No período do capitalismo desorganizado, em contraste, a pluralidade é concebida não como um problema, mas como um dado irrefutável e irreversível do mundo moderno. Se, na época do capitalismo organizado, o estado de bem-estar apresentou-se como organizador da contingência, seu progressivo desmonte, a partir dos anos I960, colocou em xeque a centralidade das categorias que lhe eram subjacentes, em especial aquelas derivadas do mundo do trabalho.

As abordagens contemporâneas da Sociologia que pretendem compreender o mundo de hoje têm que lidar tanto com a multiplicidade de fatores causais quanto com a multiplicidade de critérios que formam e conformam os grupos sociais, suas ideias e seus comportamentos.

Se, antes, a ocupação, a classe ou a política - Durkheim, Marx e Weber, respectivamente forneciam os paradigmas por meio dos quais se explicavam os nexos identitários dos grupos sociais, hoje, a análise sociológica se vê obrigada a lidar com a realidade de indivíduos e grupos sociais que se definem segundo múltiplos critérios, tal como nos sugere Homi Bhabha (2007, p. 25):

As grandes narrativas conectivas do capitalismo e da classe (...) não fornecem, em si próprios, uma estrutura fundamental para aqueles modos de identificaçáo cultural e afeto político que se formam em torno de questôes de sexualidade, raça, feminismo, o mundo de refugiados ou migrantes ou o destino social fatal da AIDS.

Por outro lado, o colapso dos regimes comunistas do Leste Europeu, seguido do avanço da maré neoliberal (ANDERSON, 1995, p. IO; BRUNHOFF, I992, pp. 73-74; FioRI, I995, pp. 22I-224; Jobert \& ThÉreT, 1994, pp. 22-23; VeLASCO E CrUZ, 2007, pp. 19-22) deixou órfă parte expressiva de uma geraçáo para a qual a alternativa comunista fornecia o principal mecanismo identitário, pois sequer esses sujeitos ainda vislumbram a possibilidade de uma grande transformação.

De qualquer modo, predominava, entre eles, a crença de que o triunfo revolucionário da esquerda levaria a uma automática resolução de "conflitos menores", como, por exemplo, as tensóes étnicas e de gênero. Ora, a eclosão de nacionalismos na Europa Oriental, após 1989, mostrou que tais conflitos, de forma alguma equacionados, foram apenas reprimidos, mascarados por Estados altamente centralizados. À abertura sucedeu-se a explosão8.

A centralização estatal, característica do processo de formação do Estado moderno, tornase alvo de críticas contundentes, seja à direita ou à esquerda do espectro político. Trata-se da formaçáo de "um grande consenso em torno da descentralizaçáa" (ARRETCHE, I996, p. 44) que denuncia o triunfo daquela liberdade negativa (BERLIN, I98I), enunciada por Benjamin Constant em I8I9: se a originalidade da época moderna reside na separação da esfera de exercício da liberdade civil da esfera do interesse público, os indivíduos modernos, preocupados com seus interesses privados, delegam ao Estado a consecução dos assuntos públicos (CONSTANT, 1985).

$8 \mathrm{O}$ caso Iugoslavo, nos anos I990, talvez seja aquele que ilustra paradigmamente esse fenômeno. 
A característica fundamental desse modelo é a ausência de instâncias mediadoras das relaçôes entre o Estado e os indivíduos - náo à toa, o grande padrão desse tipo de administraçáo pública vem a ser o Estado-Providência. Porém, em uma sociedade plural, como esse Estado pode responder a demandas particulares?

No que se refere ao espaço privado, também são levantadas relevantes mudanças. As relaçōes familiares constituem um dos principais exemplos: se à modernidade organizada correspondia o modelo da família nuclear, a modernidade desorganizada recusa-se a fornecer um padrão correto para as famílias. Ao contrário, múltiplas formas familiares convivem no mesmo espaço, sem que haja uma orientação diante do modelo ideal.

Tal transformação das relaçôes familiares pode ser vista como uma consequência direta de outro fenômeno bastante discutido na literatura sociológica recente: o descentramento do sujeito (BHABHA, op. cit.; HALL, 2000; 2008). Distanciando-se da perspectiva iluminista, com seu indivíduo centrado, coeso e racional, o indivíduo contemporâneo concebe sua identidade como uma "celebraçẫo móvel" (HALL, 2000, p. 13). Trata-se da negação de qualquer concepçáo evolucionista de sujeito. Se essa perspectiva era compreensível em uma sociedade ainda presa a padrôes rígidos de ser no mundo (Domingues, 2000, p. 49), a intensa pluralização presente no capitalismo desorganizado permite-nos uma gama de experiências concomitantes que nos leva a uma permanente (re)construçáo de nossas identidades. Em outras palavras, na contemporaneidade, o conceito de identidade cede lugar ao de processos identitários. Por conseguinte:

Se sentimos que temos uma identidade unificada desde o nascimento até a morte é apenas porque construímos uma cômoda estória sobre nós mesmos ou uma confortadora "narrativa do eu". A identidade plenamente unificada, completa, segura e coerente é uma fantasia (HALL, 2000, p. I3).

Aos pensadores contemporâneos caberia, portanto, uma rearticulaçáo de suas bases teóricas, de modo a procurar responder demandas sociais que vêm se expressando de modo cada vez mais pontual. Assim, argumenta Santos, é necessário que sejamos capazes de dissolver o potencial transformador da modernidade em diversas pequenas transformaçōes, que respondam a demandas específicas reclamadas por atores igualmente específicos (SANTOS, op. cit., pp. 9I-99).

\section{V}

Rosanvallon concebe $A$ Crise do Estado-Providência como uma tentativa de, se não responder, ao menos esclarecer tais questôes. Como ele mesmo afirmou alguns anos após a publicaçáo desse livro,

(...) durante os anos oitenta, as ideologias e as grandes sínteses macroexplicativas recuaram largamente na sociedade francesa. (...) Que a divisa republicana - Liberdade, 
Igualdade, Fraternidade - tenha sempre uma forte consistência, certo; mas pode-se dizer que ela encarne verdadeiramente valores subversivos? (RosANVALLON et al., I988, pp. 136-137 e I4I).

Mas quais seriam, então, os atuais valores subversivos? Para ele, as possibilidades de transformaçáo da sociedade passam, necessariamente, por uma redefiniçáo do conceito de solidariedade, pois a crise do Estado-Providência não poderá ser corretamente abordada apenas acentuando-se suas limitaçóes econômicas. Esse reducionismo impede que a tratemos como aquilo que de fato ela representa, a saber:

A equação econômica dos anos 70 não pôde, nos anos 90, encontrar resposta exclusivamente no campo financeiro. É no nível da sociedade e das relaçóes sociais que ela se resolve. O verdadeiro desafio é o de um novo contrato social entre indivíduos, grupos e classes. O principal bloqueio do Estado-Providência é, finalmente, de ordem cultural e sociológica. (...) Essa crise deve ser compreendida simultaneamente como crise de um modelo de desenvolvimento e crise de determinado sistema de relaçôes sociais (Rosanvallon, I997, p. 8).

Apreendendo historicamente a formação do Estado-Providência, Rosanvallon concebe-o como um desdobramento do Estado-protetor liberal que se forma quando a sociedade deixa de ser pensada como um corpo para se concebida como um mercado. Nesse movimento, o Estado torna-se o contraponto necessário à reduçáo das desigualdades produzidas pelo mercado, cabendo a ele administrar os riscos. Mas continua-se, fundamentalmente, dentro da lógica liberal utilitária, para a qual a sociedade equivale a um conjunto de indivíduos. Consequentemente, o EstadoProvidência dialoga com cada membro da sociedade isoladamente, ao mesmo tempo em que fornece soluçóes universais para todos. Conforme acentua o próprio Rosanvallon,

O Estado-protetor, como Estado fiscal, só pode construir-se libertando cada vez mais os indivíduos dos grupos sociais reais (...), nos quais se inserem as trocas que ele náo controla. (...) $\mathrm{O}$ Estado-Providência limita-se a prosseguir e a ampliar este movimento de proteção do indivíduo como figura central do social. Seu objetivo é livrá-lo das redes de solidariedade constrangedoras e aleatórias nas quais ainda se inserem: o Estado-Providência quer libertar o indivíduo simplificando o social. (...) a liberdade é concebida como exaltaçăo do indivíduo integral. (...) Não há mais o intermédio do social (Ibidem, pp. 34-35).

Mas, em uma sociedade cada vez mais plural, torna-se difícil para o Estado responder a demandas específicas sem instâncias que promovam o diálogo entre ele e os particulares. Universal por princípio, o Estado precisa permitir o desenvolvimento de mecanismos que 
promovam maior descentralização das decisóes de modo que seja possível à sociedade resolver seus problemas pontualmente.

$\mathrm{Na}$ tentativa de formular uma alternativa aos modelos polares estatismo/privatismo, Rosanvallon investe na proposta de uma refundação do pacto social que tenha como base uma nova concepçáo de solidariedade, já que, para ele, a crise do Estado-Providência representa, primordialmente, uma crise do modelo de solidariedade automática por ele produzido. Em outras palavras, torna-se necessária a criação de instâncias específicas, nas quais os indivíduos possam se constituir como grupos de interesse e, a partir daí, não só levar suas demandas ao Estado, mas, principalmente, exercitar uma democracia de caráter participativo, que permita maior visibilidade social - distante, portanto, do restrito modelo representativo do Estado-Providência.

Repensar a solidariedade representa, segundo Rosanvallon, abordar o paradoxo do capitalismo desorganizado: em uma sociedade pluralizada e fragmentada, a igualdade não tem mais o papel de formadora de identidade - o que equivale a questioná-la como finalidade social. Em suas palavras:

A "demanda de igualdade civil ou política" traduz-se pela determinação de uma norma idêntica para todos. A igualdade tem como objetivo a abolição radical das diferenças de estatuto civil ou político. A demanda de igualdade econômica ou social se apresenta de um outro modo: ela se exprime como vontade de reduçáo das desigualdades. Os dois procedimentos não são simétricos: produçáo de igualdade geradora de identidade em um caso, redução da desigualdade, no outro, sem fixação de um objetivo gerador de identidade (Ibidem, 1997, p. 29).

A partir desse diagnóstico, Rosanvallon propóe uma redefinição das relaçōes entre o Estado e a sociedade que englobe uma articulação entre três princípios: socialização, descentralização e autonomização. O primeiro teria como objetivo a desburocratização e a racionalizaçáo das funçôes coletivas; o segundo implicaria reduzir a distância entre os serviços públicos e os usuários; a autonomizaçáo, finalmente, visaria à transferência de tarefas públicas para coletividades não públicas. $\mathrm{O}$ teórico francês crê que esses princípios teriam como consequência "um tríplice movimento de redução da demanda do Estado, de reencaixe da solidariedade na sociedade e de produção de uma maior visibilidade social" (Ibidem, p. 86), respectivamente.

VI

Tocqueville e Rosanvallon refletem, obviamente, a partir de realidades distintas: o que o primeiro via como ameaça surge aos olhos do segundo como a realidade na qual estamos inseridos. Ainda que Rosanvallon escreva quase um século e meio após Tocqueville e que, portanto, sua análise reflita necessariamente o desenvolvimento das Ciências Sociais nesse longo período, 
suas preocupações podem ser interpretadas à luz dos conceitos de despotismo democrático e tirania da maioria.

Conforme exposto, com o primeiro conceito o autor de A Democracia na América pretendia alertar para os riscos presentes em uma sociedade na qual as tarefas decisórias estivessem concentradas exclusivamente na esfera estatal. Ora, a crítica que Rosanvallon imprime ao Welfare não se distancia desta ideia: o Estado de bem-estar criaria uma solidariedade automática entre si e os indivíduos isoladamente. Em ambos os autores, as consequências assemelham-se: a ausência de poderes intermediários entre o Estado e os indivíduos produziria uma sociedade civil apática, desinteressada pelas questóes públicas.

Quanto à tirania da maioria, apesar de também visível em Rosanvallon, verifica-se uma importante diferença em relaçáo a Tocqueville: para este, ela estava diretamente ligada à ameaça de uma república de moldes rousseaunianos, regida pelo dogma da vontade geral, e a única forma de evitá-la seria o estímulo ao facciosismo - o que talvez não seja exagero chamar de produção artificial de diferenças.

No contexto em que escreve Rosanvallon, caracterizado pelo pluralismo societário, as diferenças já estão reconhecidas, não havendo o risco de formação de um grande consenso majoritário que suplante as divergências. Ao contrário, o desafio que hoje se impóe é o de pensar um modelo de sociedade civil que possibilite o exercício da diferença, e não apenas que a estimule.

No entanto, parece haver um abismo entre essa sociedade plural e fragmentada e o modelo do Estado-Providência, ainda ligado a concepçôes republicanas homogeneizadoras. E, nesse ponto, observa-se mais uma relevante convergência entre os dois teóricos franceses: Tocqueville afirmava que o futuro das sociedades democráticas relacionava-se ao papel que confeririam à liberdade. Rosanvallon, por sua vez, mostra a limitação de um Estado, cuja preocupação central seja a produçáo de igualdade: em uma sociedade complexa, a busca de uma identidade que unifique todos os indivíduos pode funcionar como um poderoso instrumento de limitação das liberdades. Náo à toa, ele reivindica um modelo de Estado plural, no qual a produçáo de igualdade não se confunda com a abolição das diferenças.

Em ambos, portanto, há um nexo entre centralização estatal, individualismo excessivo, homogeneização e perda de liberdade. Igualmente, para eles, a possibilidade de superação desse quadro passa pela formaçáo de instâncias intermediárias entre o Estado e os cidadãos. Tocqueville reivindicava a ciência das associaçôes como a única talvez capaz de garantir a sobrevivência dos valores da liberdade no mundo democrático. Ora, relembrando, a proposta de Rosanvallon ancora-se em três pilares: redução da demanda do Estado, reencaixe da solidariedade na sociedade e produção de maior visibilidade social. Mas como aplicá-los? É o próprio Rosanvallon quem oferece uma resposta tocquevilleana à questáo:

Não há outra via possível senão aproximar a sociedade de si mesma. Trata-se de tornála mais densa, de multiplicar os locais intermediários de composição social, de reinserir os indivíduos em redes de solidariedades diretas (Ibidem, p. 90). 
A perspectiva adotada por Rosanvallon apresenta semelhanças com o diagnóstico tocquevilliano sobre a modernidade. Os dois relacionam certo recuo do Estado ao aumento da participaçáo popular. Mas, se Tocqueville parecia ainda crer na atuação de algumas inteligências privilegiadas - os magistrados -, Rosanvallon, despido de um viés aristocrático, aposta todas as suas fichas na capacidade dos cidadãos comuns. Associados, eles oferecerão a interface necessária entre o Estado e as demandas particulares dos diferentes setores da sociedade civil?.

Por outro lado, assim como Tocqueville, Rosanvallon preocupa-se deveras com a contraçáo do Estado e com a mobilização da sociedade civil, mas não avança em direção às relaçôes de mercado. A busca de uma alternativa aos polos estatização/privatização tende a reduzir-se à crítica do primeiro fenômeno. Seria simplório objetar que isso ocorre pelo fato de que Rosanvallon se insere em uma sociedade na qual os problemas distributivos foram melhor equacionados do que ao sul do Equador, até porque as crescentes levas de imigrantes à Europa têm imposto à agenda social não apenas discussóes a respeito da pluralidade das formas de vida, mas, também, sobre problemas de ordem sistêmica - para usar uma expressão táo cara à sociologia germânica - que envolvem, diretamente, questôes de cunho econômico.

Concluindo, creio que a crise de projetos à qual se refere Rosanvallon vem afetando não só seu próprio trabalho como as Ciências Sociais, de modo geral. Ele se aproxima de Tocqueville, autor importante para a compreensáo do papel da sociedade civil no mundo democrático, mas insuficiente para dar conta da grande encruzilhada na qual se encontram as Ciências Sociais, neste início de século: paralelamente à redefiniçấo da solidariedade social, é preciso reinventar as formas de abordar as relaçóes econômicas, caso contrário, o risco será o de apenas sobrecarregar a sociedade civil com funçóes antes restritas ao Estado, enquanto o mercado prosseguirá como instância privilegiada de exclusão social.

\section{FONTES CONSULTADAS}

Anderson, P. "Balanço do neoliberalismo". In: Sader, E.; Gentili, P. (Orgs.) Pós-neoliberalismo: as políticas sociais e o estado democrático. São Paulo: Paz \& Terra, I995. pp. 9-23.

Arretche, M. Mitos da descentralização: mais democracia e eficiência nas políticas públicas? Revista Brasileira de Ciências Sociais, São Paulo, n. 31, ano II, pp. 44-66, jun. 1996.

BerLin, I. Quatro ensaios sobre a liberdade. Brasília: Ed. UNB, I98I.

Besnier, J. -M. "Tocqueville et les associations". In: Goyard-Fabre, Simone et al. L'Actualité de Tocqueville (Actes du Colloque de Saint-Lô 5 septembre 1990). Caen: Centre de Philosophe Politique et Juridique de l'Université de Caen, I990.

9 Verifica-se, aqui, um paradoxo presente no projeto de Rosanvallon: no momento em que se afirma a substituiçáo do robusto sujeito iluminista pelos sujeitos descentrados é que se torna mister a participação popular de caráter decisório nos negócios públicos. 
Bнавна, H. O local da cultura. Belo Horizonte: Ed. UFMG, 2007.

Воввіо, N. et al. Dicionário de política. Brasília: Ed. UNB, I99I.

Brunhoff, S. "Néo-libéralisme et politique économique". In: Bidet, J.; Labica, G. (Dir.) Libéralisme et État de droit. Paris: Meridiens Klincksieck, 1992. pp. 73-90.

Constant, Benjamin. "Da liberdade dos antigos comparada à dos modernos". In: Zarka, Y. (Org.) Filosofia politica 2. Porto Alegre: L\&PM, 1985. pp. 9-25.

Domingues, J. “Desencaixes, abstraçôes e identidades”. In: Domingues, J.; Avritzer, L. Teoria social e modernidade no Brasil. Belo Horizonte: UFMG, 2000.

Fiori, J. L. Em busca do dissenso perdido: ensaios críticos sobre a festejada crise do Estado. Rio de Janeiro: Insight, I995.

Furet, F. "Le systhéme conceptuel de 'De la Démocracie en Amérique’". In: Furet, F. L'Atelier de l'Histoire. Paris: Flammarion, 1982.

. "L'importance de Tocqueville aujourd'hui". In: Goyard-Fabre, Simone et al. L'Actualité de Tocqueville (Actes du Colloque de Saint-Lô 5 septembre 1990). Caen: Centre de Philosophe Politique et Juridique de l'Université de Caen, I99I.

Gahyva, H. Tocqueville e Gobineau no mundo dos iguais. Dados, Revista de Ciências Sociais, Rio de Janeiro, v. 49, n. 3, pp. 553-58I, 2006.

Gobineau, A. "Essai sur l'inégalité des races humaines". In: Euvres. Tomo I. Paris: Gallimard, 1983.

Hall, S. A identidade cultural na pós-modernidade. Rio de Janeiro: DP\&A, 2000. . Da diáspora: identidades e mediaçôes culturais. Belo Horizonte: Ed. UFMG, 2008.

Hobsbawn, E. A era dos extremos: o breve século XX. São Paulo: Cia. das Letras, 2000.

Jasmin, M. Alexis de Tocqueville: a historiografia como ciência da política. Rio de Janeiro: Access, 1997.

Jobert, B.; Théret, B. "France: la consécration républicaine du neo-libéralisme”. In: Jober, B. (Org.) Le tournant neo-libéral em Europe: idées et recettes dans les pratiques gouvernementales. Paris: Harmattan, 1994. pp. 2I-85.

Lyotard, J. -F. O Pós-moderno. Rio de Janeiro: José Olympio, i986.

Madison, J.; Hamilton, A.; Jay, J. Os artigos federalistas: I75I-I836. Rio de Janeiro: Nova Fronteira, I993. 
Mazower, M. Continente sombrio: a Europa no século XX. São Paulo: Cia. das Letras, 200 .

Merquior, J. G. O liberalismo: antigo e moderno. Rio de Janeiro: Nova Fronteira, I99I.

Rosanvallon, P. A crise do Estado-Providência. Brasília: Ed. UNB, 1997.

Rosanvallon, P. et al. La République du centre. Paris: Calmann-Lévy, I988.

Santos, B. Pela mão de Alice: o social e o político na pós-modernidade. Porto: Afrontamento, 1997.

Sennett, R. O declínio do homem público. São Paulo: Cia. das Letras, I999.

Thibaudet, A. Tocqueville et Gobineau. La Nouvelle Revue Française: Gobineau et le gobinisme, Paris, n. 245, fev. 1934. (Reeditado em Colletifs Gallimard, I99i.)

Tocqueville, A. Euvres complètes: correspondance d'Alexis de Tocqueville et d'Arthur de Gobineau (tomo IX). Paris: Gallimard, I959.

. A democracia na América: leis e costumes. São Paulo: Martins Fontes, I998. A democracia na América: sentimentos e opinióes. São Paulo: Martins Fontes, 2000.

Velasco e Cruz, S. Trajetórias: capitalismo neoliberal e reformas econômicas nos países da periferia. São Paulo: Unesp, 2007.

Vollrath, E. O despotismo ocidental. Filosofia Politica, n. 3, pp. I3I-I45, 1986.

Werneck Vianna, L. “O problema do americanismo em Tocqueville”. In: Werneck Vianna, L. A revolução passiva: iberismo e americanismo no Brasil. Rio de Janeiro: Revan, [2004]. 